\title{
Sjögren's syndrome associated with systemic lupus erythematosus
}

\author{
Mehmet Taşdemir ${ }^{1}$, Chiar Hasan², Ayşe Ağbaş ${ }^{1}$ Özgür Kasapçopur ${ }^{3}$, Nur Canpolat ${ }^{1}$, Lale Sever ${ }^{1}$, Salim Çalışkan ${ }^{1}$ \\ ${ }^{1}$ Department of Pediatrics, Division of Pediatric Nephrology, İstanbul University Cerrahpaşa School of Medicine, İstanbul, Turkey \\ ${ }^{2}$ Department of Pediatrics, İstanbul University Cerrahpaşa School of Medicine, Istanbul, Turkey \\ ${ }^{3}$ Department of Pediatrics, Division of Pediatric Rheumatology, İstanbul University Cerrahpaşa School of Medicine, İstanbul, Turkey
}

\begin{abstract}
Systemic lupus erythematosus and Sjögren's syndrome are chronic auto- inflammatory disorders which can lead to serious organ damage. Although systemic lupus erythematosus and Sjögren's syndrome were previously considered two forms of the same disease because of presence of clinical coexistence of these two conditions, the view that they are two different conditions with mutual characteristics has become prominent in recent years. In this paper, we reported a 16 year-old girl who was followed up with a diagnosis of Sjögren's syndrome for six years and then was observed to have overlap of systemic lupus erythematosus. In the baseline, she did not have any clinical or serological evidence for systemic lupus erythematosus. After six year, massive proteinuria and serological findings developed and systemic lupus erythematosus nephritis was diagnosed by kidney biopsy. Currently, systemic lupus erythematosus and Sjögren's syndrome cannot be differentiated definetely. We need more valuable diagnostic and classification criteria to differentiate these two important conditions. (Turk Pediatri Ars 2016; 51: 166-8)

Keywords: Childhood, systemic lupus erythematosus, Sjögren's syndrome
\end{abstract}

\section{Introduction}

Systemic lupus erythematosus (SLE) and Sjögren's syndrome (SS) are two important conditions which show the properties of chronicity and autoinflammation. Systemic lupus erythematosus is a complex condition which especially affects young women, is characterized with a chronic course of exacerbations and remissions and may lead to serious organ damages. Sjögren's syndrome develops as a result of accumulation of lymphocytes in exocrine glands. The most common clinical findings include xerostomia and xeropthalmia which occur as a result of involvement of salivary glands and lacrimal glands. The characteristics of Sjögren's syndrome may also be observed in the other autoimmune rheumatic diseases (including rheumatic arthritis and SLE). The association of SLE and SS was mentioned for the first time in 1959 and it was even stated that SS was the benign form of SLE (1). In time, this view changed and the view that these two diseases were two different conditions, though they had mutual characteristics became prominent (2). In conclusion, it is still not clear if these two diseases are included in a single spectrum or are separate conditions which may be observed in association. Association with SLE was found in our patient who was followed up with a diagnosis of Sjögren's syndrome and this case was presented to draw attention to this issue.

\section{Case}

A 16-year old female patient presented with swelling and pain in the cheeks, cyanosis in the fingers and leg pain in Mach 2016. The patient who had a complaint of swelling and pain in the cheeks had not accepted salivary gland biopsy one year ago. She did not describe pain or erythema in her joints and had no other additional complaint.

Physical examination revealed the following findings: body weight: $26.5 \mathrm{~kg}$ ( $<3$. percentile), height $129 \mathrm{~cm}(<3$. percentile), axillary body temperature $37^{\circ} \mathrm{C}$, blood pressure $110 / 70 \mathrm{mmHg}$. Swelling and tenderness were present in the parotide region. Other system findings were found to 
be normal. Laboratory tests were as follows: hemoglobin: $11.2 \mathrm{~g} / \mathrm{dL}, \mathrm{WBC}: 4300 \mathrm{~mm}^{3}$, platelets: 26 7000, erytherocyte sedimentation rate (ESR): $61 \mathrm{~mm} / \mathrm{h}$, urea: $35 \mathrm{mg} / \mathrm{dL}$, creatinine: $0.6 \mathrm{mg} / \mathrm{dL}$, AST: $106 \mathrm{U} / \mathrm{L}$, ALT: $128 \mathrm{U} / \mathrm{L}$, total protein: $8.3 \mathrm{~g} / \mathrm{dL}$, albumin: $4 \mathrm{~g} / \mathrm{dL}$, complete urinalysis: pH: 6, density: 1 025, protein negative, urinary sediment: 2 erythrocytes, 1 leukocyte. Serologic test results were as follows: anti-nuclear antibody (ANA) positive, anti dsDNA: $4.87 \mathrm{U} / \mathrm{mL}(\mathrm{n}=<25)$, anti SSA: 5.20 index $(\mathrm{n}=<1)$ and anti SSB: 7.46 index ( $\mathrm{n}=<1)$ C3: $110 \mathrm{mg} / \mathrm{dL}(\mathrm{n}=90-180), \mathrm{C4}: 15$ $\mathrm{mg} / \mathrm{dL}$ ( $\mathrm{n}=10-40)$. Parotid gland ultrasonography revealed an enlarged parotid gland and heterogeneous parenchyma. In the light of these findings, a diagnosis of Sjögren's syndrome was made and prednisone (10 $\mathrm{mg}$, oral) and methotrexate (10 mg/week, intramuscular) treatment was initiated. Between the years of 2006 and 2012, the patient who was followed up with weekly methotrexate and low dose prednisone treatment had complaints of swelling in the parotid region and xerostomia and xeropthalmia intermittently. In December 2012, the patient presented because of swelling in the body and physical examination revealed the following findings: body weight: $48.8 \mathrm{~kg}$ (310. percentile), height $152 \mathrm{~cm}$ (3. percentile), axillary body temperature $36.4^{\circ} \mathrm{C}$, blood pressure $120 / 80 \mathrm{mmHg}$. Swelling in the parotid region and marked edema in the pretibial region were found. Other system findings were found to be natural. Laboratory test results were as follows: mild anemia (hemoglobin: $10.7 \mathrm{~g} / \mathrm{dL}$ ), ESR $(57 \mathrm{~mm} / \mathrm{h}$ ), hipoalbuminemia $(2.2 \mathrm{~g} / \mathrm{dL})$, proteinuria $(7 \mathrm{~g} / \mathrm{m} 2 /$ day), microscopic hematuria. The complement levels which were previously normal were found to be reduced [C3: $43 \mathrm{mg} / \mathrm{dL}$ ( $\mathrm{n}=90$ 180), C4: $9.2 \mathrm{mg} / \mathrm{dL}(\mathrm{n}=10-40)]$. The serologic teasts were as follows: ANA positive, anti dsDNA increased [289 U/L $(\mathrm{n}=<25)]$.

Renal biopsy was performed because of hypoalbuminemia, severe proteinuria and hypocomplementemia. Renal biopsy revealed "active diffuse global proliferative lupus nephritis (activity index: 11)" (Pathological evaluation: 13 glomerules were found on microscopic examination, sclerotic gomerulus was absent. Marked enlargement was found in all glomeruli. Wire-loop thickening was found in the basal membranes. Obstruction in the capillaries, focal intracapillary hyaline thrombi and focal cariorexis were observed. Congo was negative. Immunoflourescent examination revealed segmental- weighted IgG, IgA, IgM, C3 and $\mathrm{Clq}$ deposits in the basal membrane and mesangium).

In the light of the clinical and nephropathologic findings, it was decided that SS and SLE association was present in the patient. For treatment of SLE, intensive high dose steroid was given for three days (1 g/day, intravenously) and cyclophosphamide was given for once (1 g, intravenously). Afterwards, sixth month-induction treatment including monthly cyclophosphamide ( $1 \mathrm{~g}$, intravenous), and daily prednisone ( $1 \mathrm{mg} / \mathrm{kg})+$ hydroxychloroquine $(200 \mathrm{mg}$ ) combination was planned. In the follow-up, increased blood pressure was found and losartan $(50 \mathrm{mg})$ and nifedipine $(30 \mathrm{mg}$ ) were added to treatment. In the assessment performed after induction treatment, ANA was found to be severely positive, anti dsDNA was found to be significantly increased [63.2U/L $(\mathrm{N}:<25)]$, anticardiolipin IgM and IgG were found to be normal, C3 was found to be slightly increased $(60 \mathrm{mg} /$ $\mathrm{dL}$ ) and $\mathrm{C} 4$ was found to be increased to the normal level (13 mg/dL). Proteinuria regressed from $7 \mathrm{~g} / \mathrm{m} 2 /$ day to $1.6 \mathrm{~g} / \mathrm{m} 2 /$ day and the serum albumin level was found to be $2.9 \mathrm{~g} / \mathrm{dL}$. Low dose prednisone and mycophenolate mofetil were given as maintenance treatment. The patient who is currently receiving hydroxychloroquine, losartan and nifedipine at the same time has no complaints in the seventh month of the maintenance treatment and her blood pressure is under control. However, hypoalbuminuria $(2 \mathrm{~g} / \mathrm{dL})$ and significant proteinuria ( $1 \mathrm{~g} / \mathrm{m}^{2} /$ gün) continue. Consent was obtained from the patient and her parents.

\section{Discussion}

Sjögren's syndrome is observed rarely in the childhood age group. While extraglandular symptoms including fever and joint pain are prominent in adults, swelling in the salivary glands is the most common and sometimes the only finding in children (3). Children may be completely asymptomatic or may present with severe extraglandular involvement including interstitial nephritis (4).

Association of SLE and SS has been reported with a rate of $9-31 \%(5,6)$. The reason of this variable rate appears to be different criteria used in patient selection and in the diagnosis. The diagnostic criteria for SLE and SS have been updated for many times up to the present time (7, 8). Clinical findings are not always clear enough to make the diagnosis of systemic lupus erythematosus. In addition, there is still no international consensus in terms of the diagnosis of Sjögren's syndrome and no gold standard test has been recommended for the diagnosis. A multidisciplinary approach (including rheumatology, ophthalmology and oral health experts) is required for the diagnosis of Sjögren's syndrome. The diagnostic cri- 
teria for SS were reformulated in 2012 by The Sjögren's International Collaborative Clinical Alliance (SICCA) and presence of two of the following articles was stated to be significant: 1) Positive serology [(anti-SSA and/or anti-SSB) or (positive rheumatoid factor and $\mathrm{ANA}^{3}$ 1:320)], 2) Keratoconjunctivitis sicca, Focal lymphocytic sialadenitis on salivary gland biopsy (8). In a study conducted by Manoussakis et al. (6) in which patients with association of primary SS, SLE and SS (SLE+SS) and patients with SLE alone were evaluated, it was reported that the clinical properties belonging to SS were common symptoms of many rheumatologic conditions. In the same study, it was reported that patients with primary SS and SLE+SS had similar rates of clinical and laboratory characteristics (livedo reticularis, purpura, myositis, lung problems, leucopenia, thrombocytopenia) and interestingly renal failure and thrombocytopenia were observed with a lower frequency in patients with SLE+SS. In a study conducted recently, patients with primary SS and patients with SLE+SS were compared and it was reported that the disease occurred at an earlier age, the frequency of arthritis, leucopenia and thrombocytopenia was higher and xerostomia and interstitial lung disease were observed with a lower rate in patients with SLE+SS (9).

Since the clinical findings are similar, the serologic tests of these two conditions which are difficult to differentiate. Anti SSA and anti SSB are found with similar rates in patients with primary SS and SLE+SS and with a higher frequency in patients with $\operatorname{SLE}$ alone $(6,10)$. Presence of anti-dsDNA, antiphospholipid antibodies and reduced complement $(\mathrm{C} 3, \mathrm{C} 4, \mathrm{CH} 50)$ level should suggest the diagnosis of SLE.

In conclusion, we are not able to perfectly differentiate these two conditions at the present time, although we have a higher number of classification criteria compared to 50 years before. In addition, studies have shown that primary SS and SLE+SS may be found in association with a significant rate and it appears to be impossible to evaluate these conditions as completely different clinical conditions. The diagnostic and classification criteria should be improved further in order to definitely differentiate these two important conditions.

Informed Consent: Informed consent was obtained from patients' parents who participated in this case report.

Peer-review: Externally peer-reviewed.

Author Contributions: Concept - M.T., Ö.K.; Design - M.T., C.H.; Supervision - L.S., S.Ç.; Funding - M.T., A.A., N.C.; Ma- terials - M.T., Ö.K.; Data Collection and/or Processing - M.T., C.H., A.A.; Analysis and/or Interpretation - M.T., Ö.K.; Literature Review - M.T., C.H.; Writing - M.T.; Critical Review - Ö.K., L.S., S.Ç., N.C.

Acknowledgement: We would like to thank to the patient and her family for their permission to using their data in this case report.

Conflict of Interest: No conflict of interest was declared by the authors.

Financial Disclosure: The authors declared that this study has received no financial support.

\section{References}

1. Heaton JM. Sjogren's syndrome and systemic lupus erythematosus. Br Med J 1959; 1: 466-9. [CrossRef]

2. Scheinfeld N. Sjogren syndrome and systemic lupus erythematosus are distinct conditions. Dermatol Online J 2006; 12: 4.

3. Hara T, Nagata M, Mizuno Y, Ura Y, Matsuo M, Ueda K. Recurrent parotid swelling in children: clinical features useful for differential diagnosis of Sjogren's syndrome. Acta Paediatr 1992; 81: 547-9. [CrossRef]

4. Igarashi $\mathrm{T}$, Itoh $\mathrm{Y}$, Shimizu A, Igarashi T, Yoshizaki K, Fukunaga Y. A case of juvenile Sjogren's syndrome with interstitial nephritis. J Nippon Med Sch 2012; 79: 286-90. [CrossRef]

5. Grennan DM, Ferguson M, Williamson J, Mavrikakis M, Dick WC, Buchanan WW. Sjogren's syndrome in SLE: Part I. The frequency of the clinical and subclinical features of Sjogren's syndrome in patients with SLE. N Z Med J 1977; 86: 374-6.

6. Manoussakis MN, Georgopoulou C, Zintzaras E, et al. Sjogren's syndrome associated with systemic lupus erythematosus: clinical and laboratory profiles and comparison with primary Sjogren's syndrome. Arthritis Rheum 2004; 50: 882-91. [CrossRef]

7. Petri M, Orbai AM, Alarcon GS, et al. Derivation and validation of the Systemic Lupus International Collaborating Clinics classification criteria for systemic lupus erythematosus. Arthritis Rheum 2012; 64: 2677-86. [CrossRef]

8. Shiboski SC, Shiboski CH, Criswell L, et al. Sjogren's International Collaborative Clinical Alliance Research G. American College of Rheumatology classification criteria for Sjogren's syndrome: a data-driven, expert consensus approach in the Sjogren's International Collaborative Clinical Alliance cohort. Arthritis Care Res 2012; 64: 475-87. [CrossRef]

9. Yang Y, Li Z, Wang L, Zhang F. The clinical and laboratory characteristics of Sjogren's syndrome that progresses to systemic lupus erythematosus: a retrospective case-control study. Int J Rheum Dis 2013; 16: 173-7. [CrossRef]

10. Wahren-Herlenius M, Muller S, Isenberg D. Analysis of B-cell epitopes of the Ro/SS-A autoantigen. Immunol Today 1999; 20: 234-40. [CrossRef] 